\title{
PERANCANGAN APLIKASI KOMITE SUMBER DAYA MANUSIA BERBASIS WEB PADA PT CENDANA TEKNIKA UTAMA JAKARTA
}

\author{
Ependi $^{1}$ \\ ${ }^{1}$ Program Studi Manajemen \\ Universitas Mohammad Husni Thamrin \\ ependi71@yahoo.com
}

\author{
Muhammad Imron ${ }^{2}$ \\ ${ }^{2}$ Program Studi Teknik Informatika \\ Universitas Mohammad Husni Thamrin \\ imron.informatika@gmail.com
}

\begin{abstract}
This study aims to implement a reliable web-based online Human Resources Committee (KSDM) application system, so as to be able to produce information and reports that are faster, more accurate and relevant as needed. The research site is at PT Cendana Teknika Utama Jakarta, a company engaged in queuing equipment and website creation services. Sources and types of data used were obtained through field studies and literature studies. Among them by making observations and direct interviews on the object of research and supported by appropriate literature. While the data analysis method used is descriptive qualitative method.

From the results of the study, it was found that there were problems with the system that is currently running, including: a lot of paper was wasted due to talent scheduling using paper, the process of talent trial must be face to face, the process of making reports and printing of trial results cannot be accessed online, and etc. This online KSDM application is able to solve the above problems and anticipate them.

With the development of the Human Resources Committee application, it helps the decision-making process in finding the right supplier in procurement activities at PT. Cendana Teknika Utama. Applications support the company's operational activities so that they can run more effectively and efficiently.
\end{abstract}

Keywords: Applications, Human Resources Committee, Web

\footnotetext{
Abstrak- Penelitian ini bertujuan untuk mengimplementasikan suatu sistem Aplikasi Komite Sumber Daya Manusia (KSDM) online berbasis web yang dapat diandalkan, sehingga mampu menghasilkan informasi dan laporan yang lebih cepat, akurat dan relevan sesuai kebutuhan. Tempat penelitian adalah pada PT Cendana Teknika Utama Jakarta, perusahaan yang bergerak dalam bidang alat antrian dan bidang jasa pembuatan website. Sumber dan jenis data yang digunakan diperoleh melalui studi lapangan dan studi kepustakaan. Diantaranya
}

dengan melakukan observasi dan interview langsung pada obyek penelitian serta ditunjang dengan literatur-literatur yang sesuai. Sedangkan metode analisis data yang digunakan adalah metode kualitatif deskriptif.

Dari hasil penelitian, ditemukan kendala kendala dari sistem yang saat ini sedang berjalan, antara lain: banyak kertas yang terbuang karena penjadwalan talent menggunakan kertas, proses sidang talent harus tatap muka, proses pembuatan laporan dan cetak hasil sidang tidak dapat di akses secara online, dan sebagainya. Aplikasi KSDM online ini mampu mengatasi permasalahan diatas dan mengantisipasinya.

Dengan dibangunnya aplikasi Komite Sumber Daya Manusia ini membantu proses pengambilan keputusan dalam mencari penyedia (supplier) yang tepat dalam kegiatan pengadaan barang pada PT. Cendana Teknika Utama. Aplikasi menunjang kegiatan operasional perusahaan sehingga dapat berjalan lebih efektif dan efisien.

Kata Kunci : Aplikasi, Komite Sumber Daya Manusia, Web

\section{PENDAHULUAN}

\section{PT Cendana Teknika Utama Jakarta} adalah perusahaan yang bergerak dalam bidang alat antrian dan bidang jasa pembuatan website. Dalam bidang jasa pembuatan website ini, PT Cendana mulai bergerak pada tahun 2012. Jadi, PT Cendana masih dikatakan baru, dan butuh contoh-contoh aplikasi website agar dapat bersaing dengan perusahaan lain yang bergerak dalam bidang website.

PT. Cendana Teknika Utama yang disebut dengan PT. Cendana adalah perusahaan swasta yang bergerak di bidang pembuatan aplikasi atau 
program. Pada saat ini, PT. Cendana belum memiliki sistem yang memadai dalam pendaftaran penyedia (supplier). Penyedia masih melakukan pendaftaran tersebut secara manual, jika ingin menjadi salah satu penyedia PT. Cendana. Mereka harus mengirimkan proposal yang berisi profil penyedia, fotokopi SIUP, fotokopi akta pendirian dan akta perubahan perusahaan kepada pendukung bisnis. Dalam melakukan evaluasi kelayakan terhadap penyedia baru pun masih dilakukan secara manual, yaitu dengan mengisi formulir evaluasi kelayakan untuk penyedia baru. Catatan dari formulir evaluasi kelayakan tersebut, juga hanya diletakkan di proposal yang di berikan oleh penyedia, kemudian disimpan dalam lemari berkas. Hal ini bisa menyebabkan formulir evaluasi kelayakan dan proposal tersebut mudah hilang.

Dalam melakukan penilaian kinerja penyedia juga terjadi masalah. PT. Cendana masih melakukannya dengan cara manual, dimana petugas akan membagikan formulir penilaian kepada pihak-pihak di PT. Cendana yang berhubungan langsung dengan kontrak penyedia tersebut. Misalnya suatu divisi di PT. Cendana telah selesai melakukan kontrak dengan penyedia alat pembersih. Maka tahap pertama, petugas akan membagikan formulir penilaian kinerja penyedia kepada pemakai alat dan divisi PT. Cendana yang berhubungan dengan kontrak tersebut. Selanjutnya, formulir tersebut dikembalikan kepada petugas. Dari sisi lain, penyedia tidak bisa mengetahui bagaimana nilai kinerja mereka saat ini, karena belum adanya sistem tersebut dari pihak PT. Cendana. Oleh Karena itu, saat ini diperlukan suatu sistem yang bisa melakukan pendaftaran, evaluasi kelayakan dan penilaian kinerja penyedia secara online, sehingga proses tersebut bisa dilakukan dengan lebih mudah, dengan syarat tersedia komputer dan internet. Kelebihan lain yaitu semua data disimpan dalam database sehingga semua data tersebut dapat terdokumentasi dengan jelas, jadi tidak perlu lagi ada penyimpangan berkas proposal penyedia, evalusai kelayakan penyedia, dan penilaian kinerja penyedia, sehingga bisa dipantau siapa saja yang berhubungan langsung dengan sistem, dan pada saat dibutuhkan data tersebut bisa dipanggil kapan saja. Hal tersebut mengurangi resiko untuk kehilangan berkasberkas tersebut.

\section{METODE PENELITIAN}

Pengertian komite menurut KBBI adalah sejumlah orang yg ditunjuk untuk melaksanakan tugas tertentu (terutama dalam hubungan dengan pemerintahan). Sedangkan Pengertian sumber daya manusia atau bisa disingkat SDM (sumber daya manusia) adalah potensi yang terkandung dalam diri manusia untuk mewujudkan perannya sebagai makhluk sosial yang adaptif yang mampu mengelola dirinya sendiri serta seluruh potensi yang terkandung di alam menuju tercapainya kesejahteraan kehidupan dalam tatanan yang seimbang dan berkelanjutan. Dalam pengertian praktis sehari-hari, SDM lebih dimengerti sebagai bagian integral dari sistem yang membentuk suatu organisasi. 
Dari pengertian di atas dapat disimpulkan bahwa komite sumber daya manusia adalah sejumlah orang yang ditunjuk untuk melaksanakan tugasnya dalam mengatur SDM (sumber daya manusia) pada suatu organisasi. Adapun tujuan pembentukan komite ini adalah untuk memastikan penerapan kebijakan sumber daya manusia dilaksanakan secara optimal serta sesuai dengan arah dan strategi organisasi. Fungsi yang diemban oleh Komite ini yaitu membantu Direksi (orang yang bertanggung jawab penuh atas pengurusan perusahaan) dalam menyusun kebijakan dan strategi sumber daya manusia, memantau dan memastikan penerapan kebijakan dan strategi sumber daya manusia dilaksanakan secara konsisten, memastikan bahwa direksi mengetahui sepenuhnya perkembangan penerapan kebijakan sumber daya manusia, mengkaji dan memutuskan permasalahan yang timbul dalam penerapan kebijakan sumber daya manusia secara kasus per kasus. 


\section{HASIL DAN PEMBAHASAN}

HRD
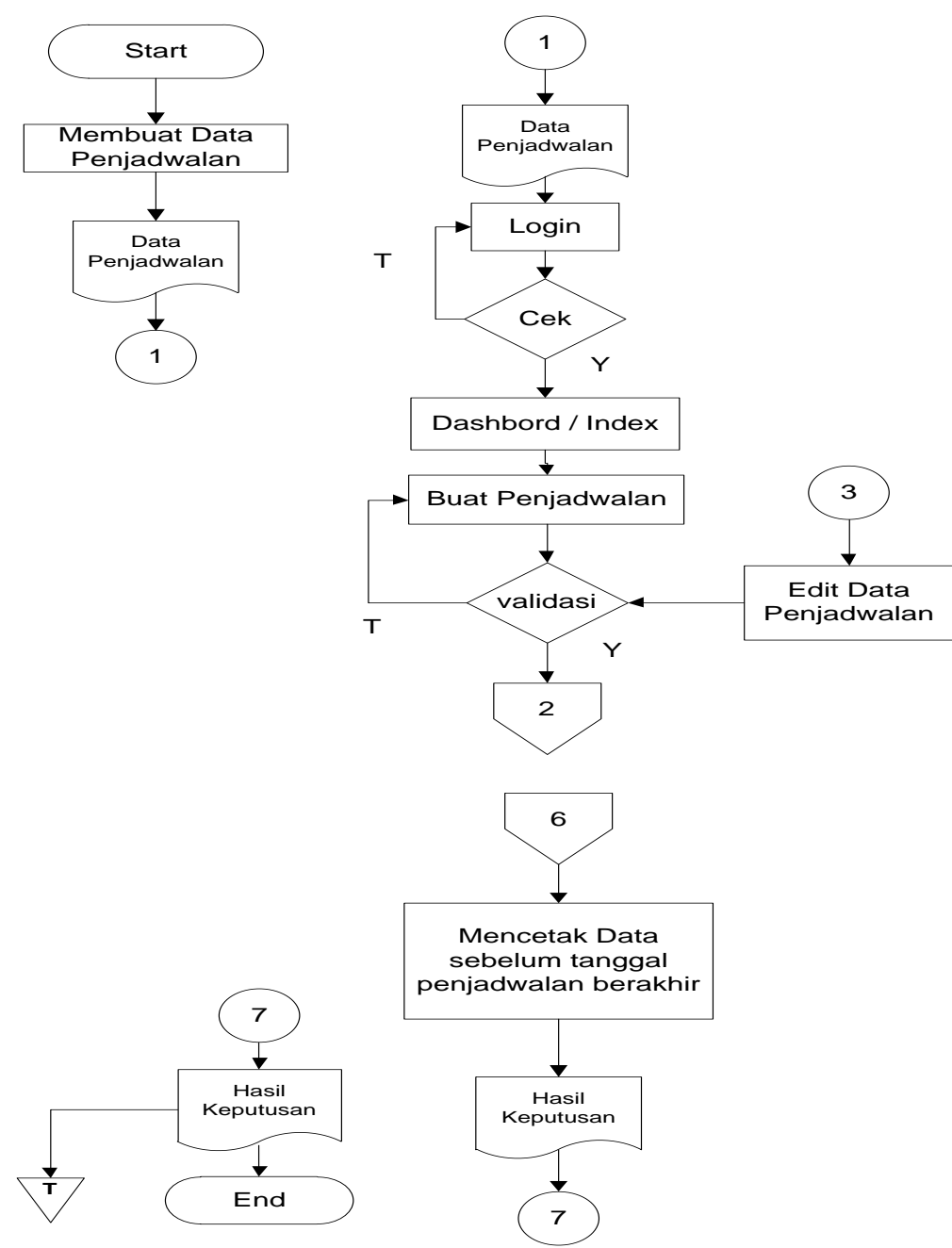

Gambar 1. Flowchart Sistem Usulan 


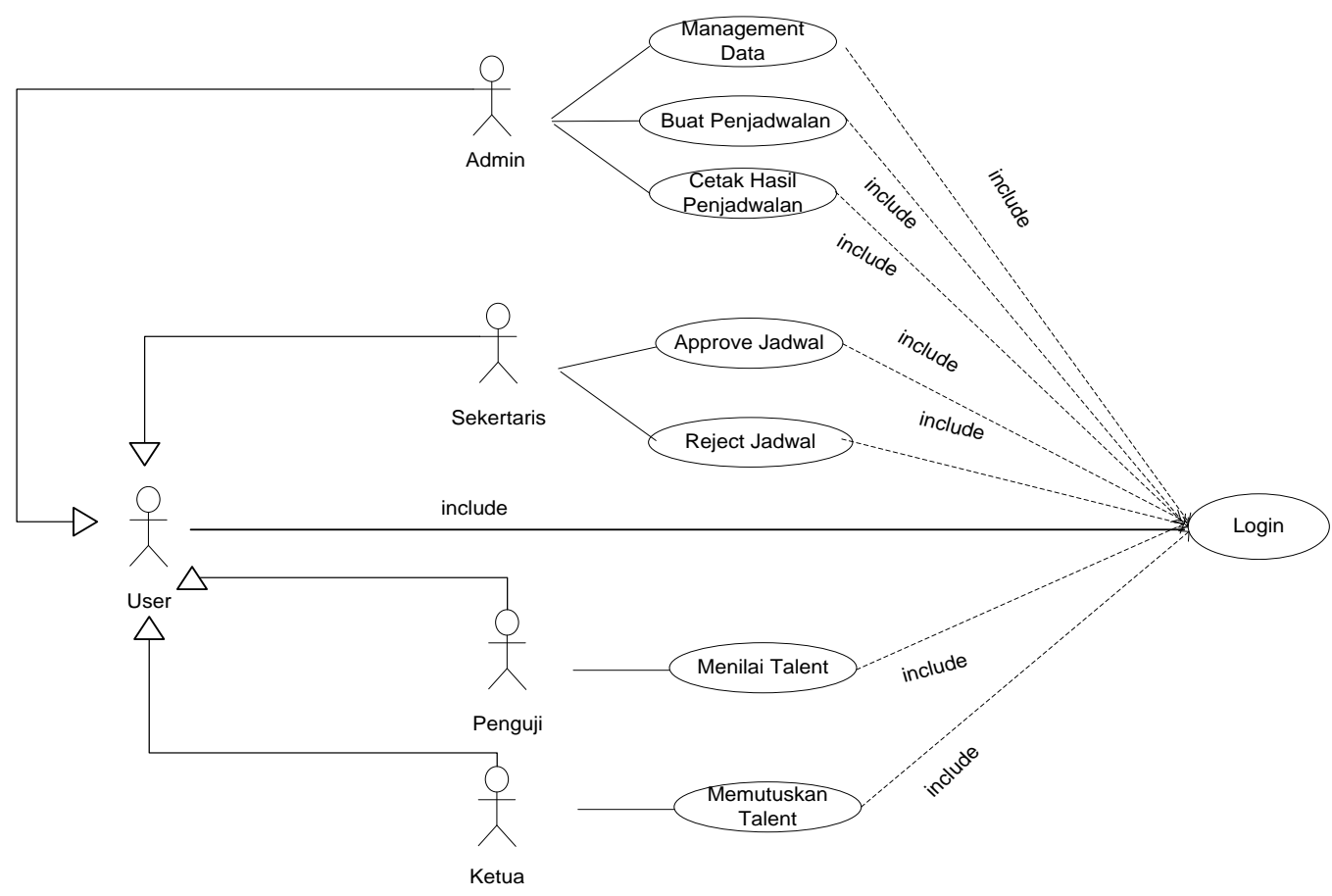

Gambar 2. Use Case Sistem Usulan

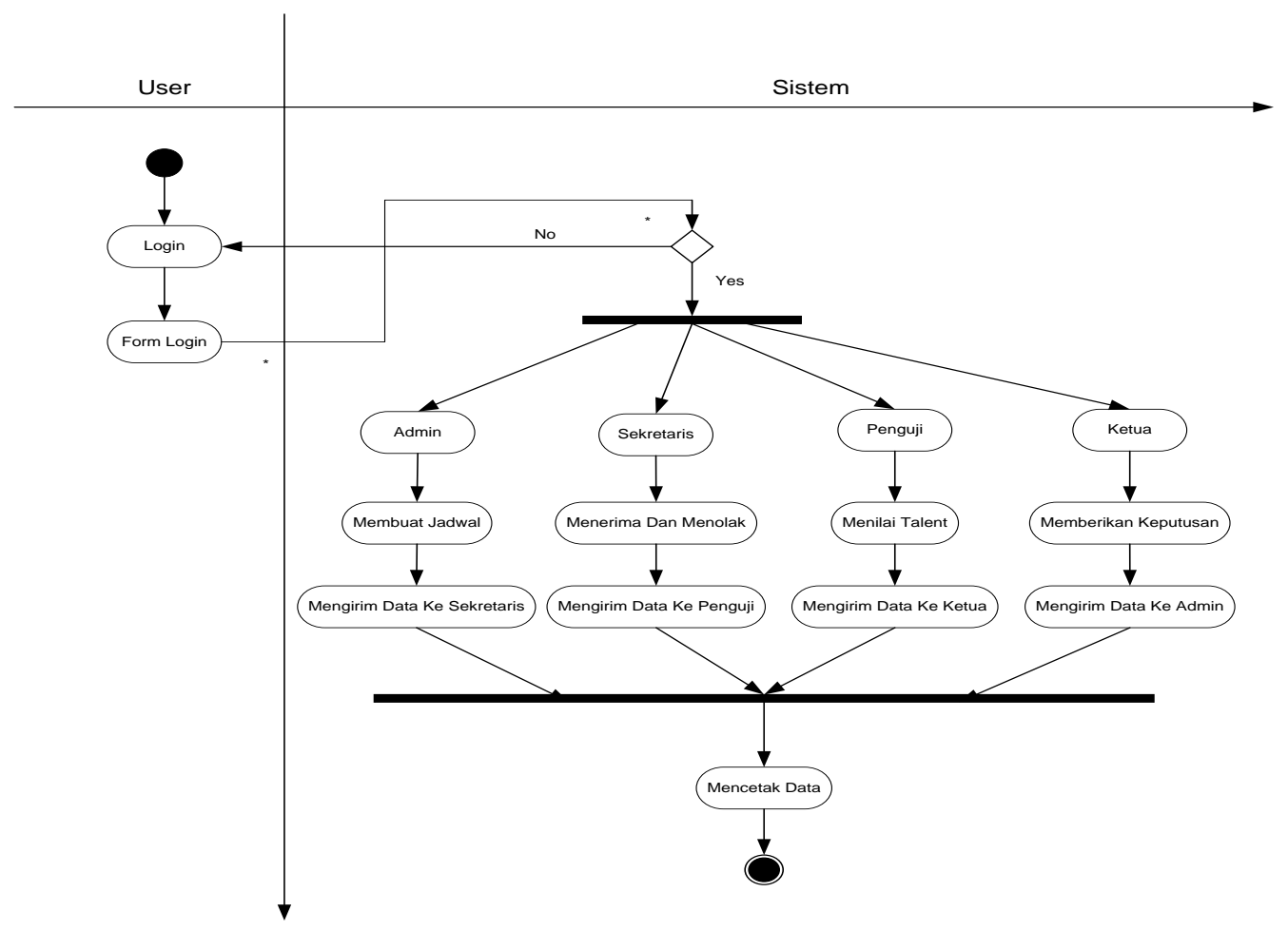

Gambar 3. Activity Diagram Sistem Usulan 


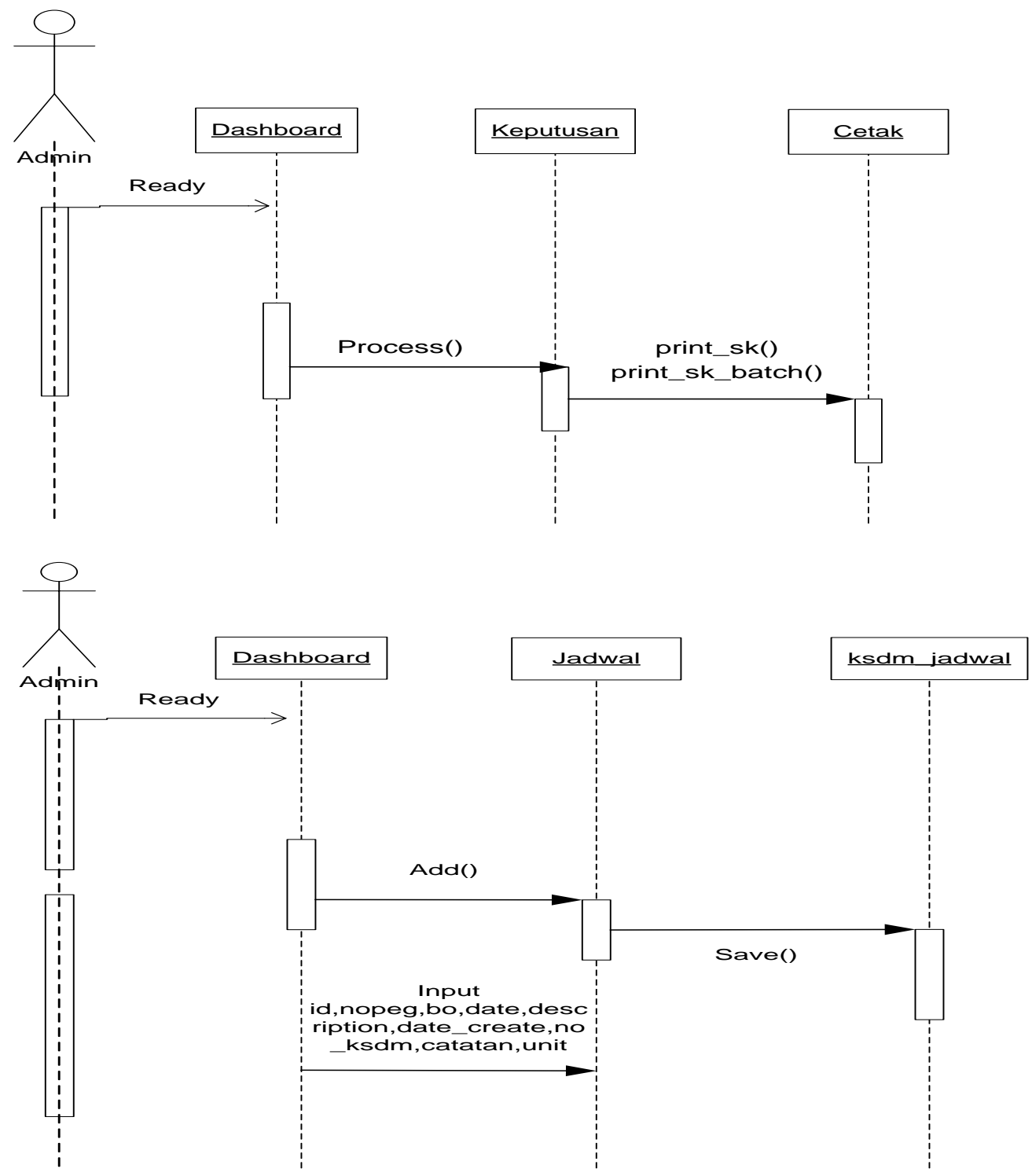

Gambar 4. Sequence Diagram Jadwal 

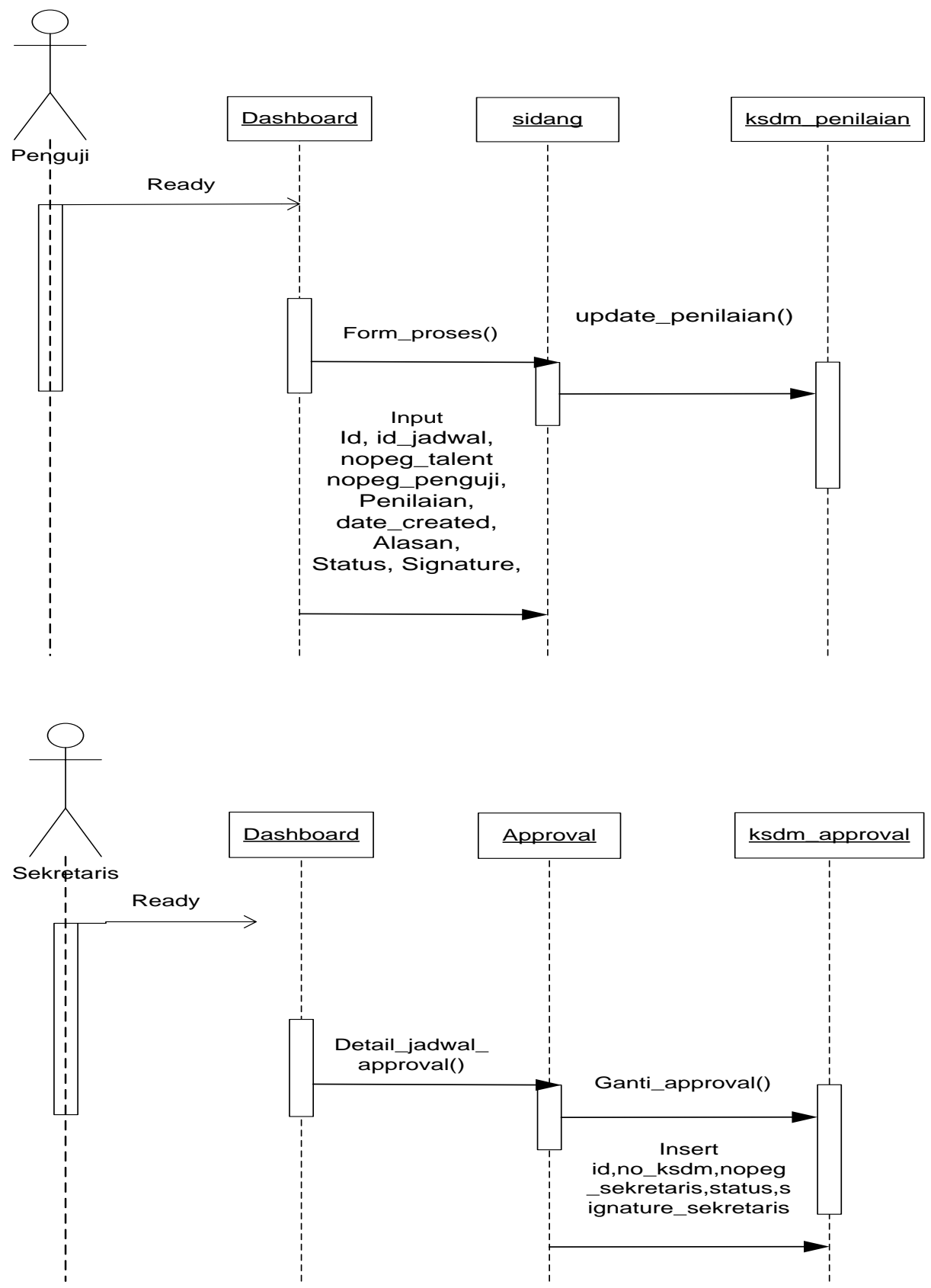

Gambar 5. Sequence Diagram Talent 


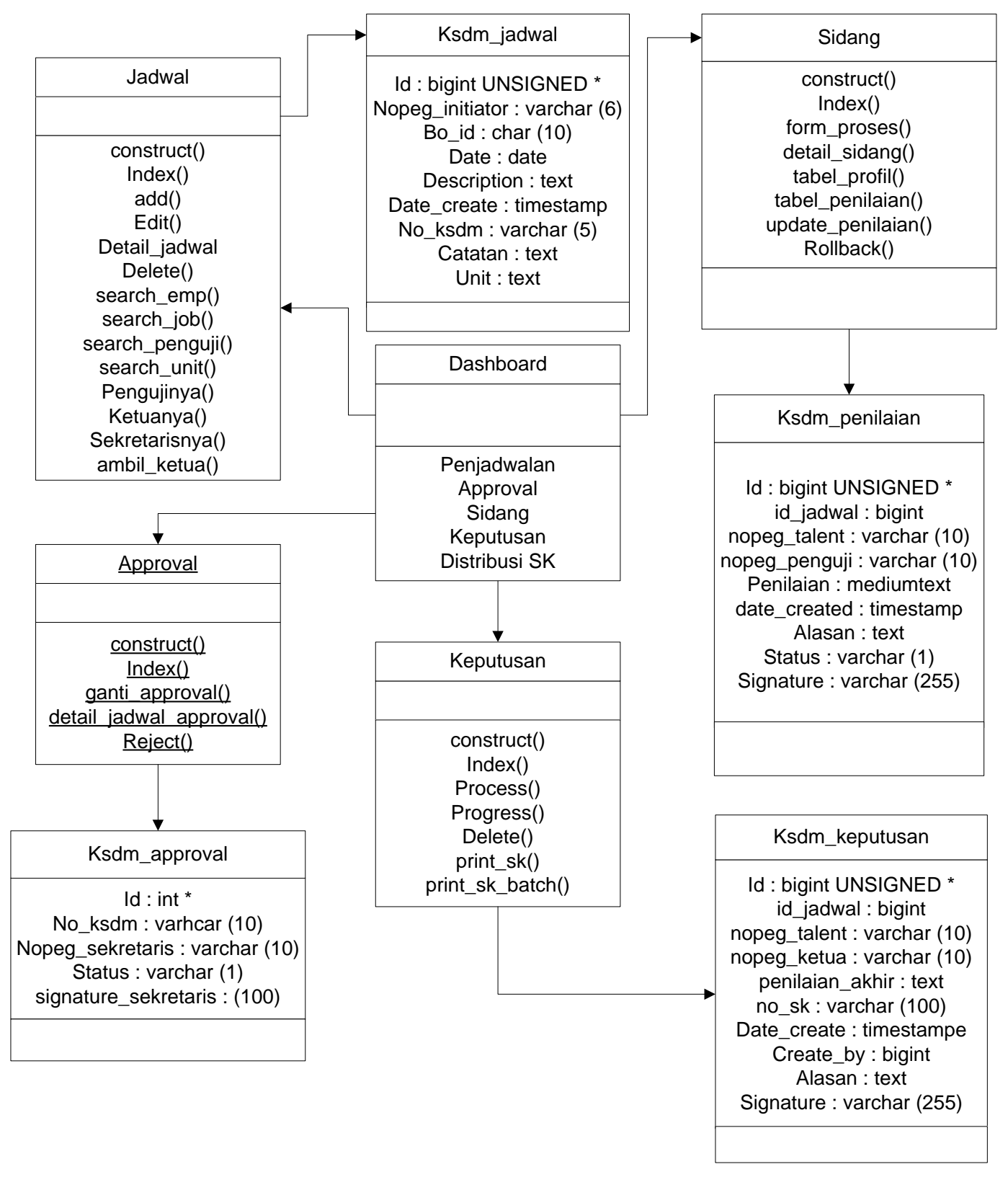

Gambar 6. Class Diagram Sistem Usulan 


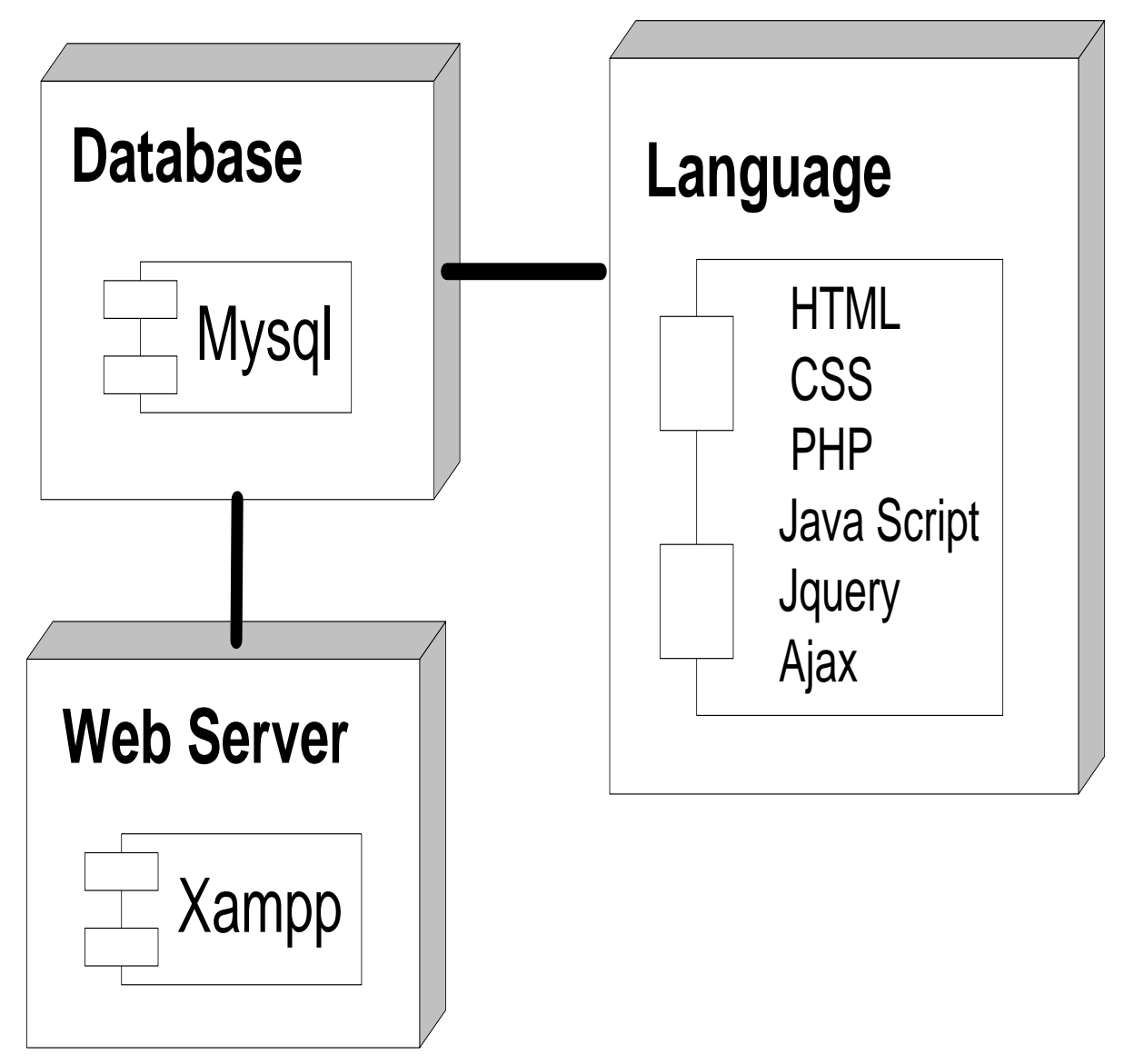

Gambar 7. Deployment Diagram Sistem Usulan

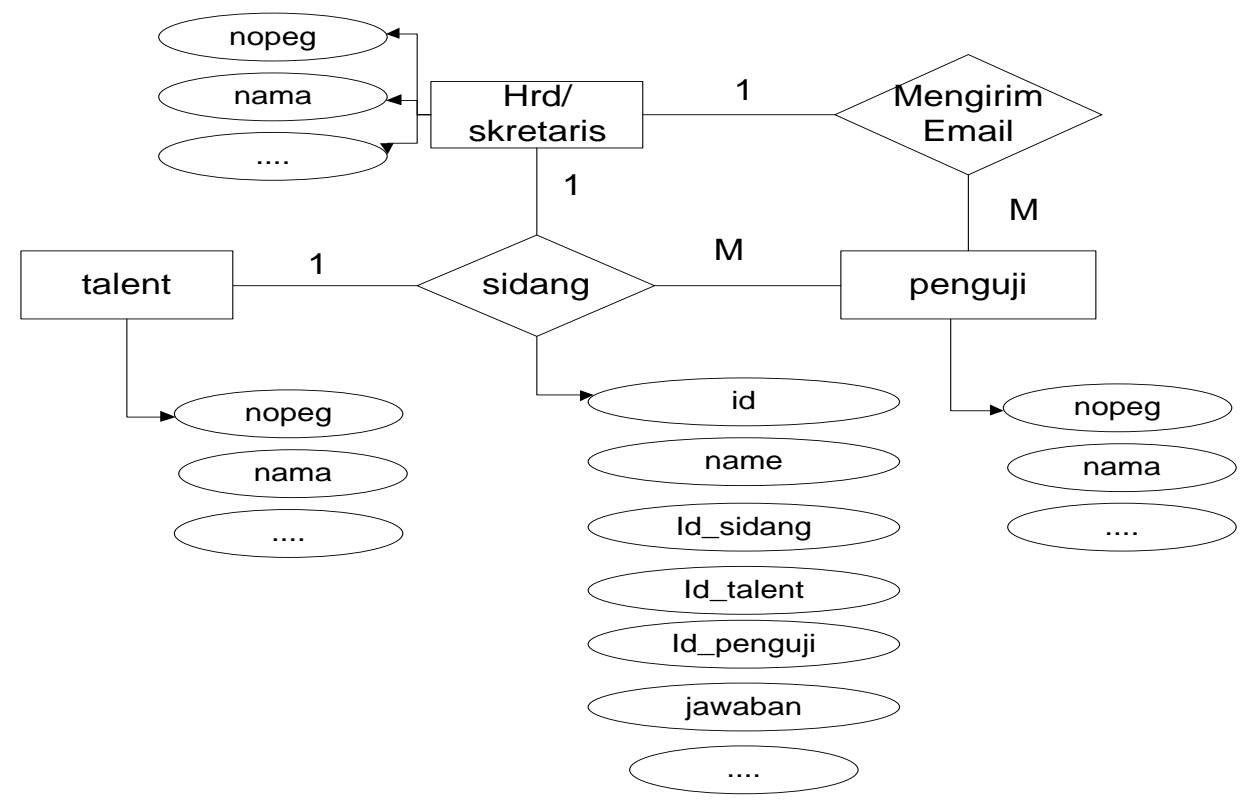

Gambar 8. Entity Relationship Diagram Sistem Usulan 


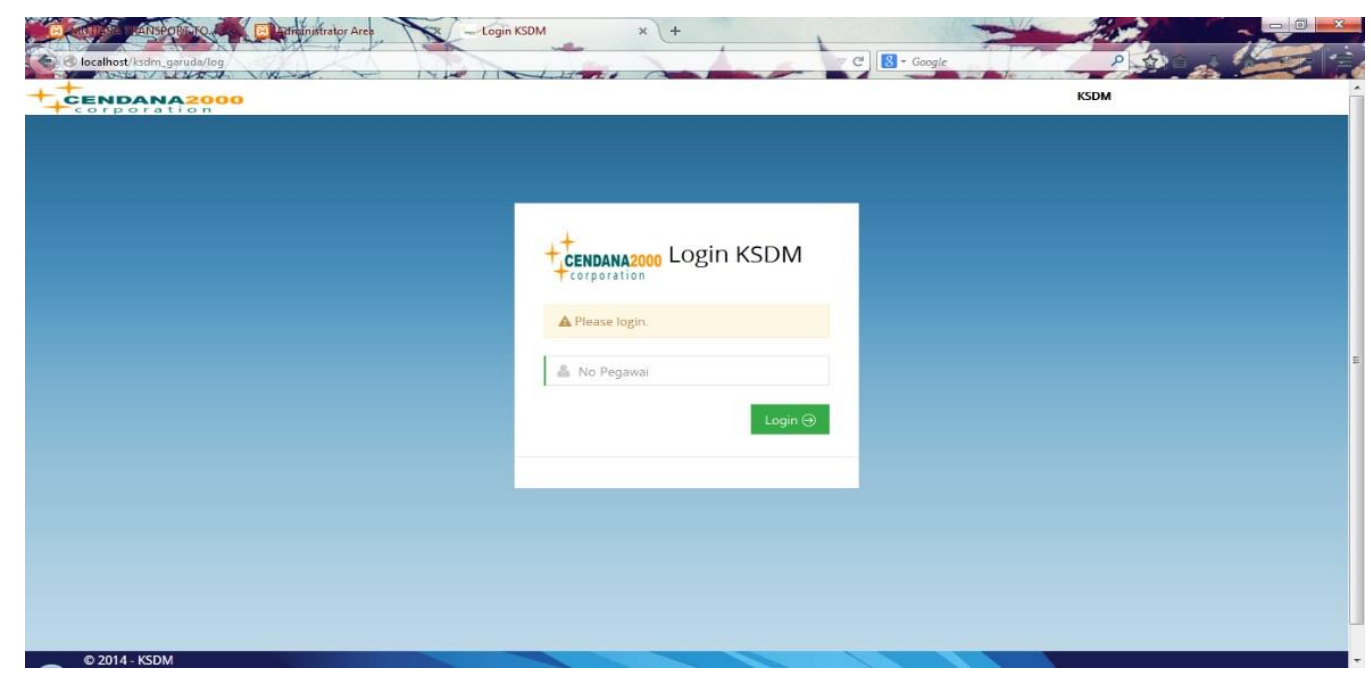

Gambar 9. Form Login

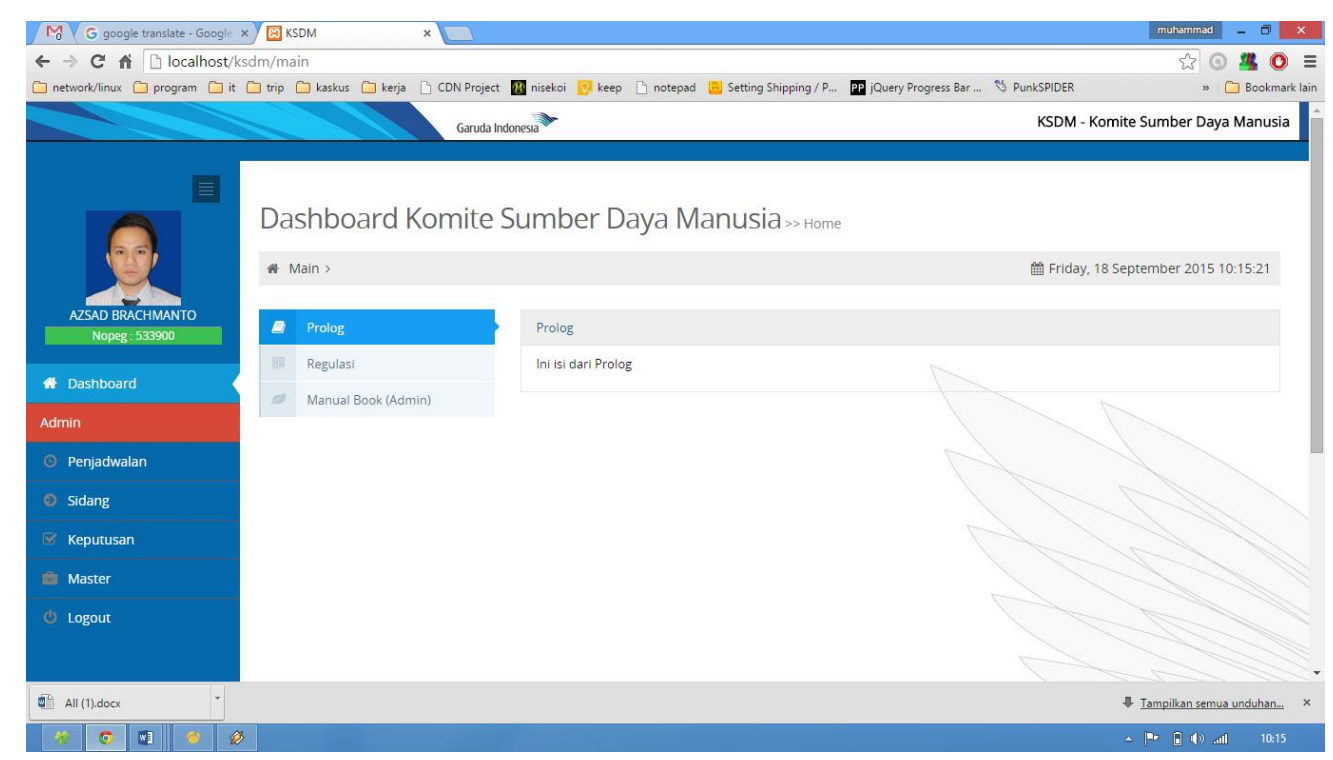

Gambar 10. Dashboard 


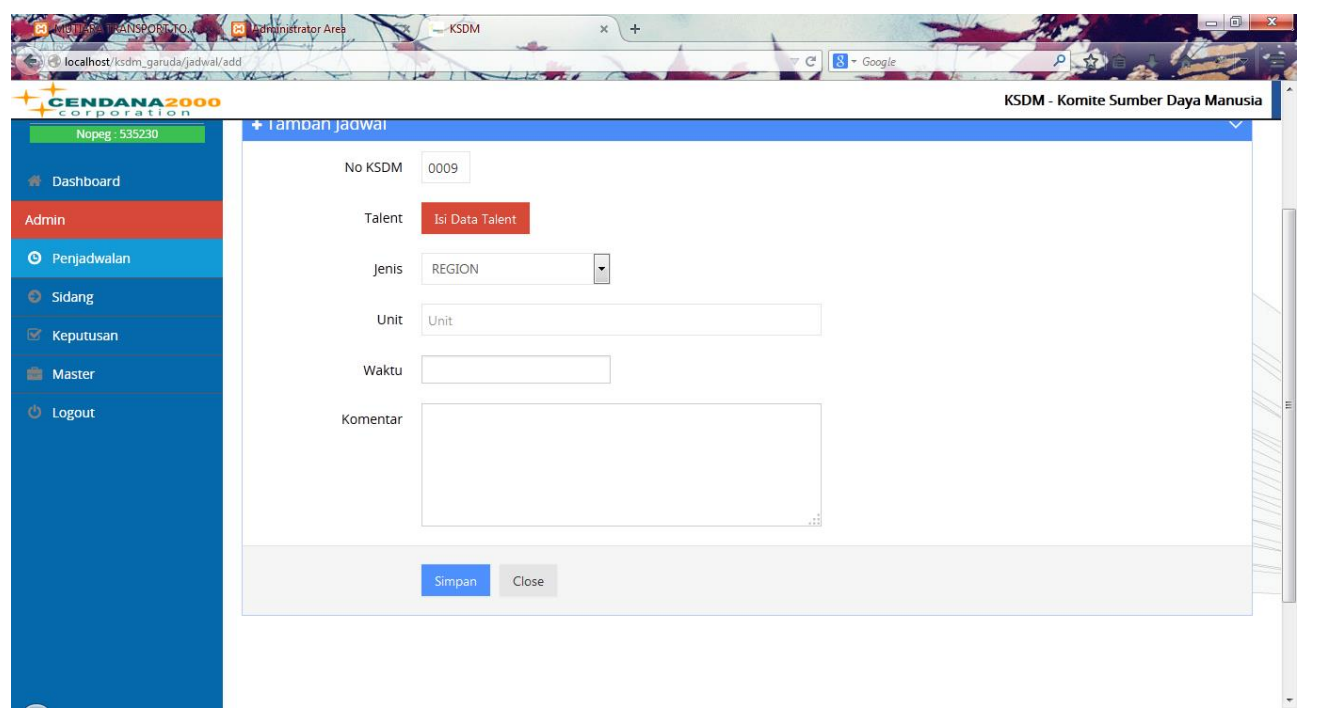

Gambar 11. Layout Tambah Jadwal

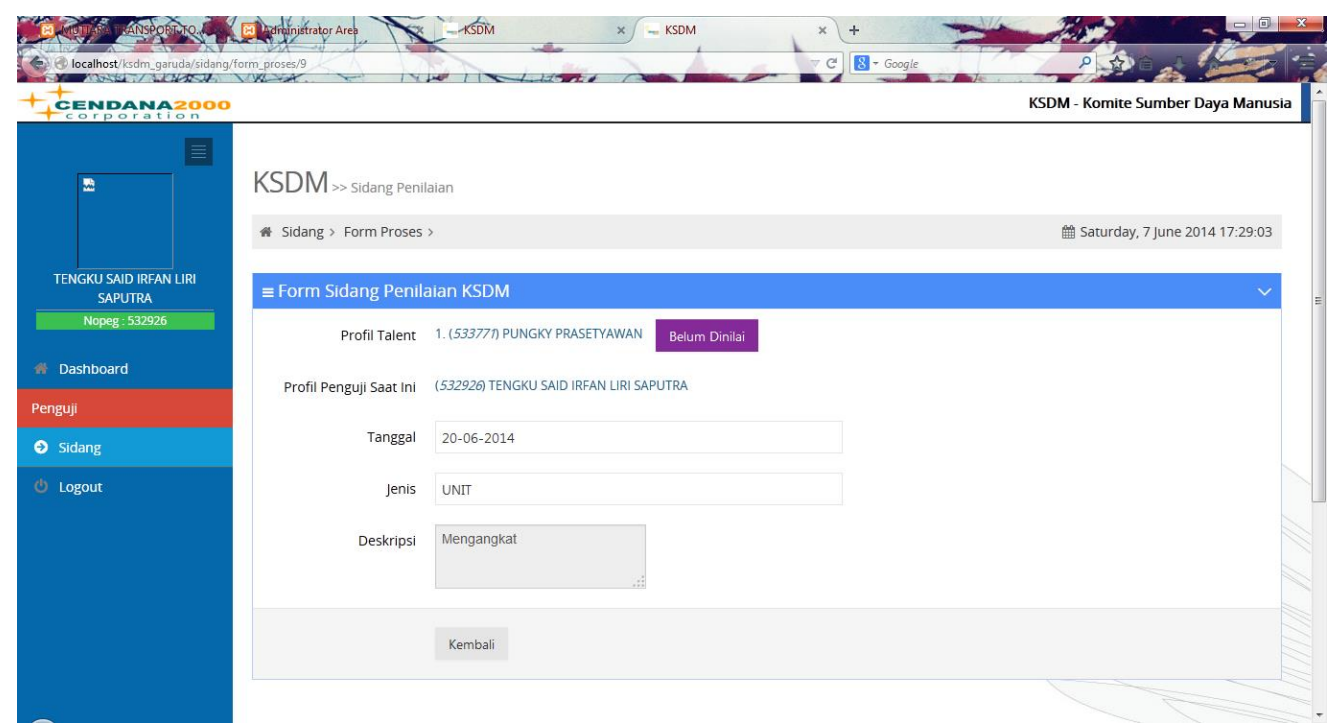

Gambar 12. Formulir Penguji 


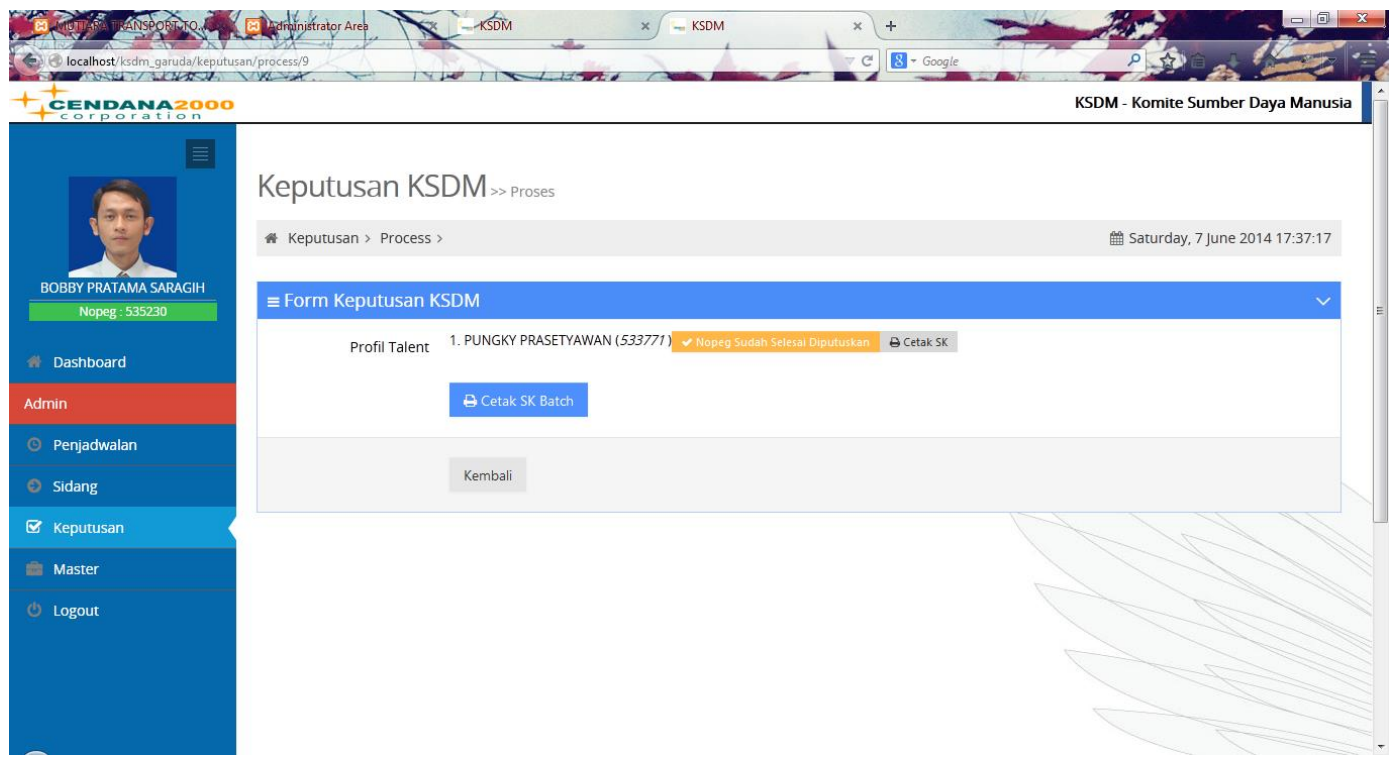

Gambar 13. Cek Hasil Sidang

\section{KESIMPULAN DAN REKOMENDASI}

Berdasarkan hasil analisis dan perancangan Sistem Informasi Aplikasi KSDM Berbasis web pada PT Cendana Teknika Utama dapat diambil kesimpulan bahwa, dengan adanya sistem Aplikasi KSDM ini, Maka:

Mengatasi masalah sistem berjalan pada komite sumber daya alam ini yang tadinya masih secara manual sehingga dirasa kurang relevan dengan berkembangnya teknologi yang semakin maju.

Masalah yang dihadapi pada sistem berjalan di komite sumber daya alam ini salah satunya adalah catatan dari formulir yang sudah terdaftar masih disimpan dalam lemari berkas, yang dapat menyebabkan formulir tersebut mudah hilang. Untuk itu diperlukan suatu aplikasi baru yang dapat diakses secara online untuk dapat mengolah data secara cepat dan akurat.

Dengan dibangunnya sistem informasi komite sumber daya manusia ini membantu proses pengambilan keputusan dalam mencari penyedia yang tepat dalam kegiatan pengadaan barang pada PT. Cendana. Serta menunjang kegiatan operasional perusahaan sehingga dapat berjalan lebih efektif dan efisien.

Aplikasi KSDM ini masih belum sempurna, Oleh sebab itu direkomendasikan untuk melakukan pengembangan agar hasilnya menjadi lebih baik dan lebih optimal. Adapun rekomendasinya yaitu :

Sebagaimana layaknya pengalihan suatu sistem dari tidak online ke sistem yang online, maka yang pertama kali harus diperhatikan adalah ketersediaannya semua perangkat keras yang diperlukan untuk mengoperasikan sistem ini.

Pemeliharaan sistem juga harus diperhatikan untuk menghindari terjadinya kerusakan sistem baik pada perangkat lunak maupun perangkat kerasnya.

Pada sistem ini sebaiknya admin selalu memantau dan memaintance Aplikasi KSDM 
untuk para penguji yang belum melakukan sidang. Keamanan sistem harus lebih ditingkatkan lagi agar tidak terjadi sesuatu yang tidak diinginkan.

\section{REFERENSI}

A.C. Aditya. 2017. Teknik Perancangan Arsitektur Sistem Informasi. Yogyakarta : ANDI Aminudin. 2014. Cara Efektif Belajar Framework Laravel. Yogyakarta : CV. Lokomedia

A.S, Rosa, M., Shalahuddin. 2013. Rekayasa Perangkat Lunak Terstruktur dan Berorientasi Objek. Bandung: Informatika

Ayub, Pengantar Sistem Informasi. Yogyakarta: Graha Ilmu, 2012.

Akbar,Ali. 2012. 1 Menit Belajar Bikin WEB Sendiri dengan PHP, Mediakom Yogyakarta Indrajani. 2015. Database Design. Jakarta : PT. Elex Media Computindo

Kadir, Abdul. 2017. Dasar Logika Pemrograman Komputer. Jakarta : PT. Elex Media Komputindo

Kusbianto, Debby. 2010. Analisis dan Perancangan Sistem Informasi. STMIK: Yadika Bangil.

Pudjo, Prabowo. Menggunakan Unified Modelling Language (UML), Bandung: Informatika, 2011.

Riyanto. Sistem Informasi Penjualan dengan PHP dan Mysql. Yogyakarta: Gava Media, 2011.

Sarosa, Samiaji. 2017. Metodologi Pengembangan Sistem Informasi. Jakarta : Indeks
Setiawan, Didik. 2017. Buku Sakti Pemrograman Web, HTML, CSS, PHP, MySQL \& Javascript. Yogyakarta : PT, Anak Hebat Indonesia

Subagja Anton. 2018. Membangun Aplikasi Web dengan Metode OOP. Jakarta : PT. Elex Media Komputindo

Sutabri, Tata. 2012. Analisis Sistem Informasi. Yogyakarta : Andi

Sutarman. 2012. Pengantar Teknologi Informasi. Jakarta : Bumi Aksara

Yasin, Verdi. 2012. Rekayasa Perangkat Lunak Berorientasi Objek. Jakarta : Mitra Wacana Media

Yudhanto, Yudo. dan Adi Prasetyo Helmi. 2018. Panduan Mudah Belajar Framework Laravel. Jakarta : PT. Elex Media Komputindo

Yakub, Pengantar sistem informasi. Yogyakarta: Graha Ilmu, 2012. 